BMC

Evolutionary Biology

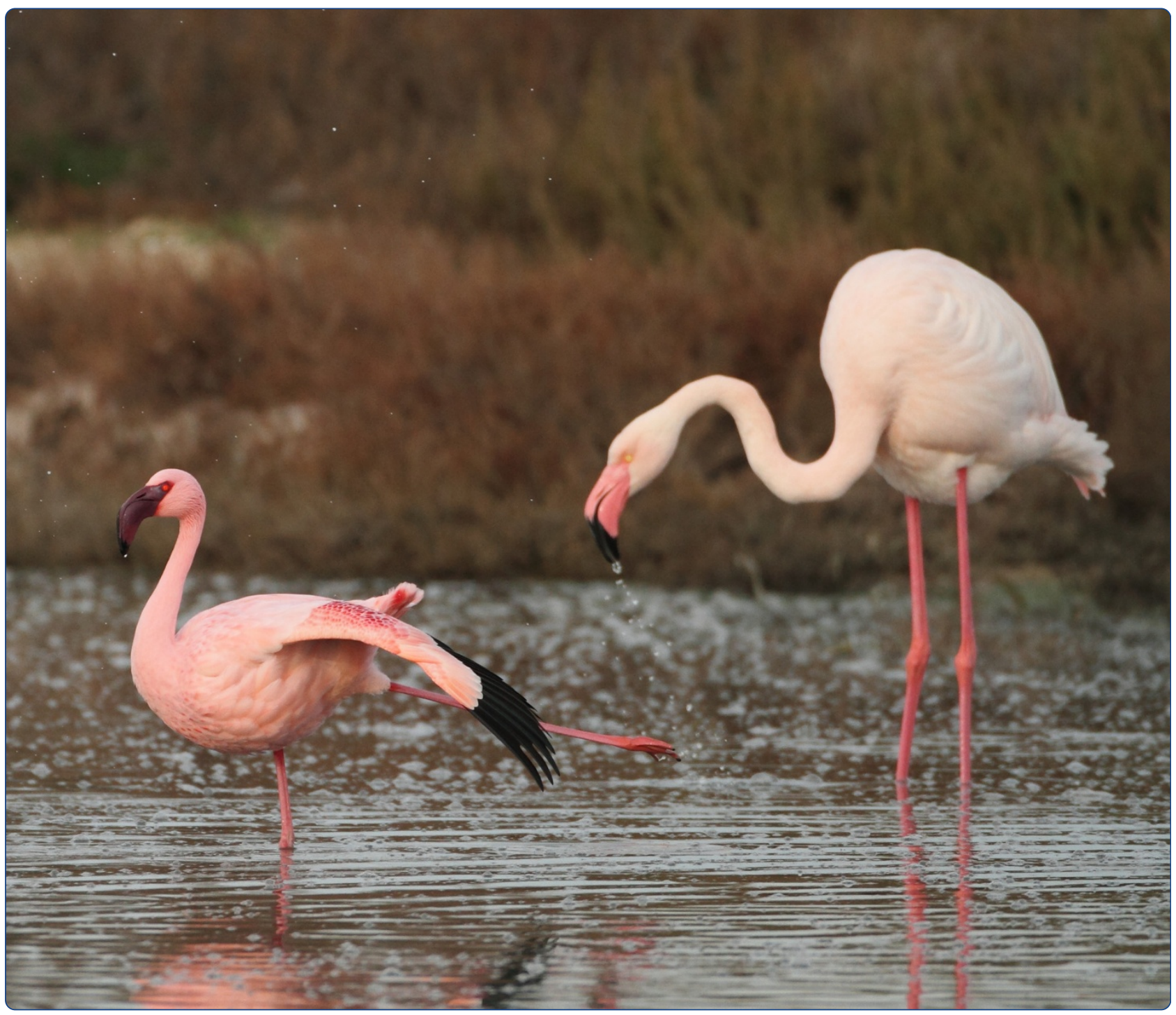

A multi-locus inference of the evolutionary diversification of extant flamingos (Phoenicopteridae)

Torres et al.

C Biomed Central 


\title{
A multi-locus inference of the evolutionary diversification of extant flamingos (Phoenicopteridae)
}

\author{
Chris R Torres ${ }^{1}$, Lisa M Ogawa ${ }^{1}$, Mark AF Gillingham ${ }^{2,3,4}$, Brittney Ferrari ${ }^{1}$ and Marcel van Tuinen ${ }^{1 *}$
}

\begin{abstract}
Background: Modern flamingos (Phoenicopteridae) occupy a highly specialized ecology unique among birds and represent a potentially powerful model system for informing the mechanisms by which a lineage of birds adapts and radiates. However, despite a rich fossil record and well-studied feeding morphology, molecular investigations of the evolutionary progression among modern flamingos have been limited. Here, using three mitochondrial (mtDNA) markers, we present the first DNA sequence-based study of population genetic variation in the widely distributed Chilean Flamingo and, using two mtDNA and 10 nuclear (nDNA) markers, recover the species tree and divergence time estimates for the six extant species of flamingos. Phylogenetic analyses include likelihood and Bayesian frameworks and account for potential gene tree discordance. Analyses of divergence times are fossil calibrated at the divergence of Mirandornithes (flamingos + grebes) and the divergence of crown grebes.

Results: mtDNA sequences confirmed the presence of a single metapopulation represented by two minimally varying mtDNA barcodes in Chilean flamingos. Likelihood and Bayesian methods recovered identical phylogenies with flamingos falling into shallow-keeled (comprising the Greater, American and Chilean Flamingos) and deep-keeled (comprising the Lesser, Andean and James's Flamingos) sub-clades. The initial divergence among flamingos occurred at or shortly after the Mio-Pliocene boundary (6-3 Ma) followed by quick consecutive divergences throughout the Plio-Pleistocene. There is significant incongruence between the ages recovered by the mtDNA and nDNA datasets, likely due to mutational saturation occurring in the mtDNA loci.

Conclusion: The finding of a single metapopulation in the widespread Chilean Flamingo confirms similar findings in other widespread flamingo species. The robust species phylogeny is congruent with previous classifications of flamingos based on feeding morphology. Modern phoenicopterids likely originated in the New World with each sub-clade dispersing across the Atlantic at least once. Our divergence time estimates place flamingos among the youngest families of birds, counter to the classical notion of flamingos as among the oldest based on biogeography and the fossil record. Finally, we designate 'Phoeniconaias' as a junior synonym of 'Phoenicoparrus' and redefine the latter genus as containing all flamingos more closely related to Phoenicoparrus andinus than Phoenicopterus roseus.
\end{abstract}

Keywords: Flamingo, Phylogeny, Divergence time, Biogeography, Fossil, Bill, Filter feeding

\footnotetext{
* Correspondence: vantuinenm@uncw.edu

${ }^{1}$ Department of Biology and Marine Biology, University of North Carolina

Wilmington, Wilmington, North Carolina, USA

Full list of author information is available at the end of the article
} 


\section{Background}

Flamingos are a unique order (Phoenicopteriformes) of birds with a highly specialized ecology but their evolutionary history remains poorly understood and until recently has only been informed by the fossil record. Flamingos are traditionally perceived as among the oldest lineages of living birds with reports of flamingo-like birds appearing in the fossil record as early as the late Cretaceous (e.g. [1]). However, the earliest birds reliably placed as stem phoenicopteriforms (family Palaelodidae) first appear in the early Oligocene of Europe [2] and the earliest members of the crown family (Phoenicopteridae) appear during the OligoMiocene of the Old World [3-5], suggesting an age for the family on par with most other major familial divergences within Aves [6]. Notably, Harrisonavis croizeti, an apparently morphologically modern flamingo from the Oligo-Miocene of France, suggests the modern flamingo divergence occurred in the Old World as early as the late Paleogene [3].

Recent fossil and molecular work have shed new insight into phoenicopterid origins and cast doubt on the classical notion of flamingos as a particularly ancient lineage among the storks, herons and ibises (Ciconiiformes). Most notably, molecular [7-11] and morphological [12,13] studies have supported a sister relationship between flamingos and grebes (Podicipediformes) as the clade Mirandornithes [14]. However, despite these advances, the exact age and phylogeny of modern flamingos remains to be robustly tested and several questions about flamingo evolution are in need of further investigation: (1) how do the six extant species of flamingos relate to each other, (2) how long ago did these divergences occur, and (3) where did crown Phoenicopteridae originate?

Sibley and Ahlquist [15] represents the only genetic study that addresses these questions. This study, based on differences in hybridization strength between genomic DNA of different species, documented a shallow age among five species and (the formerly classified) two subspecies (Phoenicopterus ruber ruber and P. ruber roseus) that likely form a single genus comprising two distinct sub-clades. This division is congruent with the organization by Jenkin [16] of flamingos into two groups reflecting mandibular morphology and feeding strategy: the Lesser, Andean and James's Flamingos (the so-called deep-keeled group) have bulbous bills in cross-section suited to filtration of smaller food items (e.g. blue-green algae and diatoms); the remaining species (shallowkeeled group) have more compact bills in cross-section suited to filtration of larger food items (e.g. mollusks and crustaceans). Further morphological variation within the two sub-clades is not completely known [17].

Intraspecific genomic variation in each flamingo species is also incompletely known but is an important consideration when investigating morphological and geographic origins of species with wide ranges. Recent population genetics studies have identified a lack of genetic structure within the Greater [18]; Remi Wattier, pers. comm. and Lesser [19] Flamingos, both species with extensive ranges in the Old World. It is unlikely that the restricted breeding distribution $[20,21]$ on the Andean altiplano promotes genetic structure in the Andean and James's Flamingos. Except for captive populations [22,23], the population genetics of the American and Chilean Flamingos remains uninvestigated.

The present study has three aims: 1) to assess intraspecific mitochondrial variation within the widespread New World Chilean Flamingo through the use of three mtDNA markers and museum skins collected throughout the range; 2) to test the phylogenetic relationships among modern flamingos through the use of a multilocus (10 nDNA and two mtDNA markers) and varied analytical (Bayesian, maximum likelihood framework) approach; and 3) to estimate the divergence times of living flamingo species from the resulting species tree calibrated with two fossil constraints. How these results inform the taxonomic organization and biogeography of flamingos is discussed.

\section{Results}

\section{Population genetics of the Chilean Flamingo}

Sequence data for $3 \mathrm{mtDNA}$ loci were obtained and analyzed from 17-26 Chilean Flamingos representing the entire breeding range of the species except Ecuador (Additional file 1). Only two out of 18 individuals showed variation in the COI gene (one out of $142 \mathrm{bp}$, or $0.7 \%$ ), exposing the same substitution recovered previously by a DNA barcoding study of neotropical birds [24]. That study indicates the presence of only one substitution $(0.15 \%)$ in the entire barcode portion of the COI. From the current study, the common haplotype was distributed throughout the range, while the minor variant was found in an individual from Peru (this study) and in three individuals from the Argentinean Andes (this study and [24]). Both haplotypes coexist in these localities. Two additional markers that are known to be variable in related species (NADH 2, $\mathrm{n}=17$; control region, $\mathrm{n}=20$ ) failed to reveal the existence of additional mitochondrial variation.

\section{Phylogenetics}

Analysis of single loci generally failed to result in complete phylogenetic resolution, instead supporting one or few of the key nodes in the final species tree (Figure 1). None of the single locus-based gene trees (except cyt b) indicate significant conflict, rather lack of resolution, with the final multi locus-based species tree. Thus, the joint analyses of loci that vary in mutation rate contributed to enhanced overall resolution The species topology is congruent with 


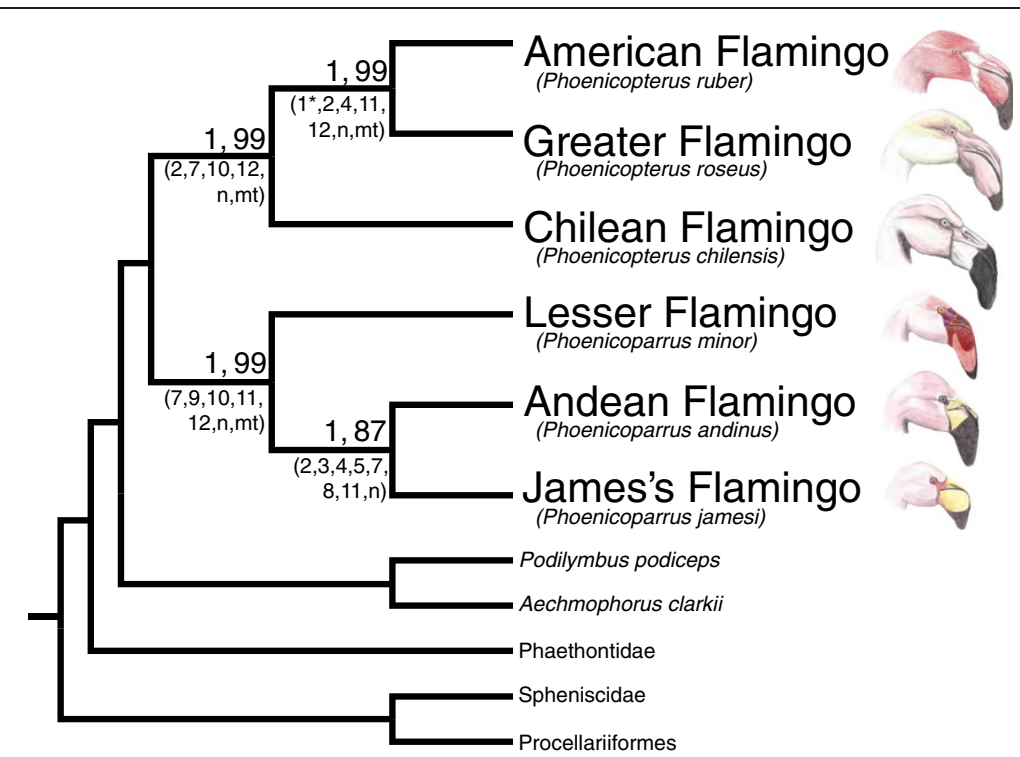

Figure 1 Relationships and ages of the flamingos. Cladogram showing the relationships of the living flamingos. The flamingos fall out in two sub-clades with high support, congruent with the topology recovered by Sibley and Ahlquist [15]. Genus Phoenicoparrus has been expanded to include all members of the deep-keeled clade (see Discussion). Posterior probabilities (Bayesian inference) and bootstrap support values (maximum likelihood) are shown above each node. Numbers and letters to the right of each node indicate individual genes and data subsets which recover that monophyletic clade. Key: 1, RHEB1; 2, TIMM17A; 3, TCF3; 4, RPS24; 5, SLC29A4; 6, NFKBIZ; 7, G3PDH; 8, myoglobin; 9, ZENK; 10, ZENK 3'UTR; 11, COl; 12, cyt b; n, nDNA subset; mt, mtDNA subset. RHEB1 failed to recover sister status between the American and Greater Flamingos in a maximum likelihood framework with high support, denoted by ' $1{ }^{*}$ '.

previous non-DNA sequence based studies [15] with flamingos breaking into two distinct clades: a shallow-keeled clade comprising (Chilean $+($ American + Greater $))$ and a deep-keeled clade comprising (Lesser + (Andean + James's)).

Additional analysis indicates that the species topology is particularly robust. The Bayes factor analysis supported partitioning of the total dataset by locus (Bayes factor $=$ 231), though both partitioned and non-partitioned BI analyses recovered the same topology with complete support (posterior probability $=1.0$ ); the $\mathrm{ML}$ analysis had $>85 \%$ bootstrap support for all nodes. A *BEAST analysis including multiple individuals for each flamingo species again recovered the same topology with complete support (posterior probability $=1.0$ ). All jackknife analyses excluding a single locus at a time from the total (nDNA + mtDNA) dataset recovered the complete topology with high $(>0.9)$ posterior probability, suggesting that no single locus was driving the results. The $\mathrm{nDNA}$ dataset recovered the same topology, while the mtDNA dataset differed only by recovering a (Andean + (Lesser + James's) $)$ clade, albeit without significant support.

Even though intra-specific variation was discovered in a set of five nDNA loci including two to three individuals per flamingo species, this variation was found to be minimal $(<0.5 \%$ in each case, Additional file 2$)$, an inference confirmed by independent cross-checking between the two genetics labs which revealed a match for all 6 flamingos. Furthermore, five of the 12 loci showed interspecific variation between the American and Greater Flamingos (0.1-1.8\%; Additional file 3), with the barcode locus (COI) $\mathrm{K} 2 \mathrm{P}$ distance indicating $1 \%$ variation.

\section{Divergence time estimation}

The dates recovered by the mtDNA dataset are consistently $\geq 2$ times the ages recovered by the nDNA dataset, while those recovered by the total dataset fall in between (Table 1). Crown-clade Phoenicopteridae likely arose at or shortly after the Mio-Pliocene boundary (3.0-6.5 mya). The deep- and shallow-keeled clades diverged in either the Pliocene or earliest Pleistocene (1.7-3.9 mya) followed by the American-Greater split (0.9-1.5 mya) and the Andean-James's split (0.5-2.5 mya). Age ranges represent the total (upper bound) and the nDNA only (lower bound) datasets. See Table 1 for divergence dating results of the all datasets (ages in bold, 95\% confidence intervals in parentheses).

\section{Discussion}

Population genetics of the Chilean Flamingo

A single metapopulation was identified across the range of the Chilean Flamingo, harboring minimal genetic variation. This finding parallels similar recent findings in other widespread flamingo species [18,19] and is consistent with the appearance of opportunistic breeding [25] and a nomadic lifestyle [26] in all flamingos. Given these results, 
Table 1 Ages for divergences within Phoenicopteridae based on 12 loci with 2 fossil calibrations

\begin{tabular}{|c|c|c|c|c|c|}
\hline \multirow[b]{2}{*}{ Divergence } & \multicolumn{5}{|c|}{ Age (95\% C.I.) Ma } \\
\hline & Total & Nuclear & Mitochondrial & Nuclear + COI & Nuclear + cyt b \\
\hline Crown & $4.37(2.38-7.16)$ & $3(1.45-5.5)$ & $6.5(3.65-10.15)$ & $4.02(2.24-6.73)$ & $\mathbf{5 . 5 9}(3.08-9.66)$ \\
\hline Phoenicopterus & $2.29(1.07-4.06)$ & $1.67(0.69-3.21)$ & $2.42(1.12-4.22)$ & $2.12(0.99-3.67)$ & $2.42(1.08-4.51)$ \\
\hline Ruber-roseus & $1.01(0.34-1.98)$ & $\mathbf{0 . 8 8}(0.25-1.87)$ & $1.18(0.45-2.2)$ & $\mathbf{0 . 9 5}(0.34-1.83)$ & $1.45(0.51-2.93)$ \\
\hline Phoenicoparrus & $2.56(1.26-4.37)$ & $1.83(0.77-3.5)$ & $4.3(2.15-6.9)$ & $2.08(1.06-3.64)$ & $3.82(1.96-6.69)$ \\
\hline Andinus-jamesi & $1.34(0.54-2.47)$ & $\mathbf{0 . 5}(0.12-1.14)$ & Not recovered & $\mathbf{0 . 8 1}(0.33-1.56)$ & $2.32(1.07-4.23)$ \\
\hline
\end{tabular}

Ages of divergences within flamingos are in bold followed by the $95 \%$ confidence intervals in parentheses. Extant flamingos likely originated at or shortly after the Miocene-Pliocene boundary, making them one of the youngest lineages among living birds. The ages recovered by the nuclear data are consistently much younger than the ages recovered by the mitochondrial data, likely the result of mutational saturation in the mitochondrial sequences.

minimal genetic structure is expected for the phylogeographically unstudied Andean, James's and American Flamingos. Thus, it is unlikely that unaccounted-for population structure impacted the results of our phylogenetic and divergence dating analyses.

\section{Phylogenetics}

Our study provides the first sequence-based molecular support for the relationships among flamingos suggested previously $[15,16]$. By contrasting the lack of full resolution for any of the individual loci with the complete resolution found for the nDNA and total datasets, the need for multiple independent loci to resolve temporally young divergences is underscored. Conflicting phylogenetic signal exists between the mtDNA loci as COI was the only single locus to fully resolve the flamingo relationships while cyt $\mathrm{b}$ recovered the Andean Flamingo at the base of the deep-keeled clade with high support. The relationships recovered by the total dataset agreed with those recovered by COI, as well as by the nDNA dataset and those recovered previously [15], indicating that the nDNA data sufficiently overpowered the conflicting cyt b signal.

The two sub-clades recovered in our analysis are congruent with the patterns detected by Jenkin [16] in mandibular morphology. The shallow-keeled clade comprises those species with bills suited to capture larger prey items and includes the Greater (Phoenicopterus roseus), American (P. ruber) and Chilean (P. chilensis) Flamingos. Within this clade, the American and Greater Flamingos are often considered sub-species (e.g. [15]). The 1\% divergence inferred from the DNA barcode locus falls in the range of expected nearest neighbor distances among sister species, such as seen commonly in waterfowl [27]. Although more sampling is needed to confirm species status, our finding of fixed mutational differences in several nuclear loci and a $1 \%$ divergence in mtDNA is consistent with treating the American and Greater Flamingos as separate species.

The deep-keeled clade comprises those species with bills suited to capturing smaller prey items and includes the
Lesser (minor), Andean (andinus) and James's (jamesi) Flamingos. These species have often been set apart from the classical genus Phoenicopterus with the Lesser placed within Phoeniconaias based on unique characteristics of the bill [28] and the Andean and James's placed together in Phoenicoparrus based on the shared absence of the hallux (hind toe) [29]. However, the morphological definition of Phoeniconaias does not seem to exclude andinus and jamesi, and the hallux of minor is reduced [16], approximating the morphological definition of Phoenicoparrus. Thus, we suggest that the division of the deep-keeled clade into two genera is arbitrary and uninformative. Instead, we suggest the placement of minor within Phoenicoparrus along with andinus and jamesi based on shared mandibular morphology, ecology and phylogenetic relatedness. We suggest the designation of Phoeniconaias as a junior synonym of Phoenicoparrus based on priority and the redefinition of Phoenicoparrus as all species more closely related to Phoenicoparrus andinus than to Phoenicopterus roseus.

\section{Divergence time estimation}

Even though the various subsets of data recovered incongruent divergence times (Table 1), all agreed on a recent divergence for crown Phoenicopteridae, indicating that living flamingos are among the youngest lineages within Neoaves. This young age is counter to the general perception of the Phoenicopteridae as among the oldest lineages of living birds based on fossil data (e.g. [1]) but is congruent with the DNA-DNA hybridization data of Sibley and Ahlquist [15], which identified the close genetic relatedness of the flamingos and predicted an age of 5-6 Ma for the basal divergence among the extant species. The nDNA dataset recovered ages significantly $(\geq 2 \times)$ younger than those of the mtDNA dataset. This pattern is likely due in part to artificial signal caused by saturation of the more quickly mutating mtDNA genes [30]. Though saturation is unlikely to be an issue with divergences as shallow as those of crown Phoenicopteridae, the use of temporally more distant calibrations external to the clade of interest (e.g. within grebes) may have introduced saturation artifact. It is likely that 
homoplasy within the relatively longer and more quicklyevolving mtDNA sequences, with more mutational sites, conflicted with the signal of the shorter and more slowly evolving nDNA sequences, resulting in artificially old age estimates. Thus, the true ages of the component flamingo divergences are probably somewhere between those predicted by the total dataset and by the nDNA dataset alone.

\section{Biogeography}

The two Old World species (Greater and Lesser) are each recovered in clades with otherwise exclusively New World distributions. The recovery of the Greater Flamingo as derived within Phoenicopterus suggests a New World origin for the shallow-keeled flamingos. The origin of Phoenicoparrus is not so straightforward, as the basal divergence within the clade spans the Atlantic. Plio-Pleistocene fossil flamingos are known only from the New World [31-37] and Australia [4,38] and the phylogenetic affinities of these species are uncertain. No flamingos occupy Australia today and it is unknown if the Plio-Pleistocene fossils represent an extension of the current distribution or if they are descendants of the species which occupied Australia in the Oligo-Miocene [4]. The New World fossil record, however, is congruent with the modern flamingo distribution and likely suggests an origin for Phoenicoparrus, and crown Phoenicopteridae, in the Western Hemisphere, followed by trans-Atlantic dispersal. Better phylogenetic resolution for the Australian forms will further inform phoenicopterid origins.

\section{Implications for the fossil record}

The phoenicopteriform fossil record is rich but poorly understood and revision will greatly advise divergence time estimation and paleo-biogeographical reconstruction for crown flamingos. The stem phoenicopteriform record is characterized by fragmentary material with only tentative assignment to the flamingos. While the earliest palaelodids (early Oligocene) are the earliest to be reliably placed in Phoenicopteriformes, Juncitarsus [39,40] (but also see [41]), Elornis and Agnopterus [42] from the middle to late Eocene of North America and Europe may be earlier members and perhaps more appropriate fossil calibrations for Mirandornithes. Better understanding of the Plio-Pleistocene record may also provide internal calibrations for crown flamingos.

Finally, while we present the first information on the timing of diversification and specialization within crown flamingos, better understanding of interspecific variation (particularly with respect to the filter feeding mandibular morphology) is necessary to interpret the ecological significance of these results. Likewise, revision of the stem phoenicopteriform fossil record is necessary to place these ages in a more meaningful context. Most notably, the primitive flamingo Harrisonavis croizeti from the Oligo-Miocene of Europe displayed a mandibular morphology approximating that of modern flamingos $[3,43]$. Reassessment of this material, and new descriptions of contemporaneous taxa, will inform the state of flamingo specialization at this point and better constrain the rate of specialization within the Phoenicopteridae.

\section{Conclusions}

Chilean Flamingos show no evidence of population structure across their entire range, a condition similar to other widely-distributed flamingo species. The six living species of flamingos fall into two clades reflecting differences in bill morphology and feeding ecology. We propose slight reorganization of flamingo taxonomy to indicate these differences: the Greater, American and Chilean Flamingos comprise genus Phoenicopterus while the Lesser is moved to genus Phoenicoparrus (= 'Phoeniconaias') along with the James's and Andean Flamingos. The living species diverged from each other $\sim 4.37$ million years ago, followed by Phoenicoparrus ( 2.56 mya) and Phoenicopterus ( 2.29 mya).

\section{Methods and materials}

\section{Population genetics methods}

Field sampling of all flamingo populations remains impractical for logistic reasons, including geographic inaccessibility and conservation protection. Sampling from captive birds alone is not guaranteed to capture species-wide variation due to a persistent lack of information regarding the geographic origins of the ancestors of captive populations. To assess phylogeographic structure, we thus set out to sample museum specimens of Chilean Flamingos with known locality. Available DNA barcodes from Chilean Flamingos suggest the presence of at least two haplotypes in Argentina [19] but no data is available from other portions of their range. Thus, we examined portions of three mitochondrial genes through amplification from historic toe pads from Chilean Flamingos $(n=27)$ with known localities (see Additional file 1 for specimen information). The samples used spanned nearly the entire range known of Chilean Flamingos (excluding Ecuador) and were obtained through several museum loans. The three loci were chosen based on known intraspecific variation in flamingos (COI in Chilean and Greater Flamingos; NADH 2 in Lesser Flamingos) or known high rates of mutation (control region). Primers were manually generated using sequences available in GenBank (Additional file 4). In order to prevent contamination, ancient DNA procedures for extraction and amplification were followed [44] (see Additional file 5 for methods). 


\section{Taxonomic sampling (phylogenetics)}

Tissue samples were obtained for each flamingo species (Additional files 6, 7). Podilymbus podiceps and Aechmophorus clarkii were included to represent the basal split within grebes [45]. The sister taxon to (flamingos + grebes) remains controversial but the tropicbirds (Phaethontidae) are consistently found as close relatives $(e g .[7,9,10])$ and were used as an outgroup. Penguins (Sphenisciformes) and tubenoses (Procellariiformes) were included as representatives of the waterbird clade (eg. [9-11]). Sample collection was reviewed and approved by the Centre de Recherche sur la Biologie des Populations d'Oiseaux (CRBPO, Musée National d'Histoire 126 Naturelle, France) under the personal permit (number 405) of Alan Johnson and Arnaud Béchet and by USDA permit (number 102976) of MVT.

\section{Genomic sampling}

Genomic DNA was extracted from tissue samples using the DNeasy Tissue Kit (Qiagen) and was amplified for 10 nuclear and two mitochondrial loci from one individual per species, which comprised the primary dataset (Table 2). Two additional nuclear loci were also amplified to test intraspecific variation among flamingos only. See Additional file 4 for primer sequences. The nuclear loci consisted primarily of intronic regions with primers designed using an exon-primed intron spanning approach and sequences from the chicken and zebra finch genome (following [46]). Polymerase chain-reaction (PCR) amplifications were car-

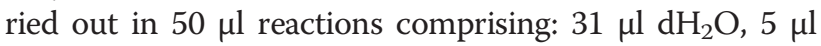

$10 \times$ detergent- and $\mathrm{Mg}^{+}$-free reaction buffer, $5 \mu \mathrm{l} \mathrm{MgCl}$ (25 mM), $1 \mu \mathrm{l}$ dNTP (10 mM each), $2.6 \mu \mathrm{l}$ each primer, $0.2 \mu \mathrm{l} \mathrm{Hot} \mathrm{MultiTaq}$ (US DNA) polymerase $(5 \mathrm{u} / \mu \mathrm{l})$ and $2.5 \mu \mathrm{l}$ DNA template $(20 \mathrm{mM})$. Thermocycling comprised an initial denaturation at $95^{\circ} \mathrm{C}$ for 5 min followed by $35-40$ cycles of annealing at $95^{\circ} \mathrm{C}$ for $30 \mathrm{sec}$, extension at $50^{\circ} \mathrm{C}$ for $30 \mathrm{sec}$ and denaturation at $95^{\circ} \mathrm{C}$ for $40 \mathrm{sec}$, followed by a final annealing/extension at $72^{\circ} \mathrm{C}$ for $5 \mathrm{~min}$. Excess dNTPs and primers were removed from PCR product by addition of $1.45 \mu \mathrm{l}$ Exonuclease 1 (Fermentas; $5 \mathrm{u} / \mu \mathrm{l}), 2.85 \mu \mathrm{l}$ FastAP (Thermo Scientific) shrimp alkaline phosphatase $(1 \mathrm{u} / \mu \mathrm{l})$ and $2.85 \mu \mathrm{l} \mathrm{dH} 20$ and held at $37^{\circ} \mathrm{C}$ for $30 \mathrm{~min}$ and then $80^{\circ} \mathrm{C}$ for $15 \mathrm{~min}$. Product was sequenced offsite at MacroGen USA (Maryland).

Sequence data for one to two additional flamingo individuals per species for five loci (Additional file 8) were collected in the Dijon, France lab. For these samples, genomic DNA was extracted from blood samples for the Greater, American and Chilean Flamingos and feather samples for the remaining three species using a standard phenolchloroform method. PCR amplifications and product clean-up followed the same protocols as the Wilmington, US lab. Product was sequenced offsite at MacroGen Korea (Seoul).

\section{Sequence treatment and phylogenetic analysis}

Sequences were aligned within Sequencher 4.8 and alignments were confirmed within MEGA 5.2 [47] using ClustalW with default settings. Pairwise genetic distances

Table 2 Genetic loci used in the phylogenetic and divergence time estimation analyses

\begin{tabular}{|c|c|c|c|c|}
\hline Locus & Basepair length & Genomic location & Phylo. sub. model & Diverg. sub. model \\
\hline RHEB1 & 642 & Nuclear & $\mathrm{T} 92+\mathrm{G}$ & TN93+I \\
\hline TIMM17A & 516 & Nuclear & $\mathrm{K} 2 \mathrm{P}$ & HKY \\
\hline TCF3 & 601 & Nuclear & T92 & HKY \\
\hline RPS24 & 407 & Nuclear & HKY & HKY \\
\hline SLC29A4 & 524 & Nuclear & TN93 + I & TN93 + I \\
\hline NFKBIZ & 506 & Nuclear & $\mathrm{K} 2 \mathrm{P}$ & HKY \\
\hline G3PDH & 432 & Nuclear & HKY & HKY \\
\hline myoglobin & 677 & Nuclear & K2P & HKY \\
\hline ZENK & 653 & Nuclear & TN93 & TN93 \\
\hline ZENK 3'UTR & 287 & Nuclear & T92 & HKY \\
\hline $\mathrm{COI}$ & 699 & Mitochondrial & $H K Y+G$ & $H K Y+G$ \\
\hline cyt b & 1026 & Mitochondrial & $H K Y+G$ & $H K Y+G$ \\
\hline ADAMTS10 & 510 & Nuclear & $\mathrm{K} 2$ & - \\
\hline HMGB2 & 575 & Nuclear & $\mathrm{T} 92+1$ & - \\
\hline
\end{tabular}

Only the two mtDNA loci were treated as coding; the mtDNA were further partitioned by codon in the divergence time estimation analyses. Substitution models for each locus were estimated using MEGA 5.2 and the best available model was used in MEGA 5.2 and MrBayes 3.2.1 for the phylogenetic analyses and in BEAST 1.8.0 for the divergence time estimation analyses. ADAMTS10 and HMGB2 were only used in phylogenetic analysis testing flamingo intraspecific variation. Abbreviations: RHEB1, Rheb isoform 1, intron 3; TIMM17A, mitochondrial import inner membrane translocase subunit Tim17A, intron 3; TCF3, Transcription factor 3, intron 12; RPS24, ribosomal protein S24, intron 5; SLC29A4, solute carrier family 29, member 4, intron 8; NFKBIZ, Nuclear Factor of light polypeptide gene enhancer in B-cells inhibitor, zeta, intron 6; G3PDH, glyceraldehyde-3-phosphate dehydrogenase gene, intron 11; myoglobin gene, exon 2, 3 and intron 2; ZENK, zinc finger protein, exon 2; ZENK 3'UTR, zinc finger protein, 3' untranslated region; COI, cytochrome oxidase subunit I; cyt b, cytochrome b; ADAMTS10, ADAM metallopeptidase with thrombospondin, type 1 motif, intron 5; HMGB2, high mobility protein group, box 2, intron 1 . Drawings by M. McCracken. 
were calculated in MEGA 5.2 using the default Maximum Composite Likelihood substitution model except for COI, which was calculated using Kimura 2-Parameter. Maximum likelihood phylogenetic analyses were carried out within MEGA 5.2 and the loci were concatenated. Unless the dataset comprised only coding genes (ZENK, COI and cyt b), each dataset was treated as noncoding; optimal substitution models were found within the hierarchical BI and ML framework in MEGA 5.2 (Table 2) and the analysis used a nearest-neighbor-interchange heuristic search. Bootstrap support was estimated from 500 replicates using the same settings. Primary phylogenetic analyses using Bayesian inference were carried out in MrBayes 3.2.1 [48]. Datasets were fully partitioned based on the optimal substitution models estimated within MEGA 5.2. Each search comprised two concurrent runs of four chains each for $10,000,000$ generations sampled every 1,000 generations with the first 1,000,000 generations discarded as burn-in. The results of each analysis were tested for convergence of phylogenetic signal in Tracer 1.5 [49], where estimated sample size (ESS) values $>200$ were treated as reliable signal.

The primary analysis employed all $10 \mathrm{nDNA}$ and two mtDNA loci for one individual per species. All secondary analyses employed the same parameters as the primary analysis except where noted. To test for the presence of intraspecific variation, a series of singlelocus analyses were carried out using two to three sequences per flamingo species for five loci (Additional file 2). To recover individual gene trees, each locus was analyzed independently. To test the relative weight of each locus to the combined dataset, a series of analyses were run excluding a single gene at a time. To test for conflicting signal between the nDNA and mtDNA datasets, each was analyzed independently. To test for the effects of over-partitioning of the Bayesian inference analysis, a Bayesian analysis was carried out treating the total dataset as non-partitioned (as in the ML analysis). A Bayes factor analysis was carried out in Tracer 1.5 to compare the strength in phylogenetic signal of the fully partitioned and non-partitioned BI treatments.

"BEAST 1.8.0 [50] was used to test for discordance between individual gene trees and the species tree. The dataset was fully phased by individual and gene. Loci were allowed unlinked substitution models, clock models and partition trees. The optimal available substitution model was used (Table 2) and the 3 coding loci were partitioned by codon position. Each locus was allowed a lognormal relaxed clock with uncorrelated rates. Mean clock rate priors (ucld.mean) were allowed uninformative uniform distributions (Initial value $=0.05$; Upper $=1.0 \mathrm{E} 100$; Lower $=$ 0.001). A Yule speciation process was assumed. No fossil node calibrations were used. The results were tested for convergence of phylogenetic signal in Tracer 1.5.

\section{Divergence timing analysis and fossil calibrations}

Divergence time estimation analyses were carried out using BEAST 1.8.0 [51]. Loci were allowed unlinked substitution models (Table 2) and the 3 coding loci were partitioned by codon position. A lognormal relaxed clock with uncorrelated rates was assumed and a Yule speciation process was employed. The clock mean (ucld. mean) was allowed an uninformative uniform prior distribution (Initial value $=0.05$; Upper $=1.0 \mathrm{E} 100$; Lower $=$ 0.001). Taxa were divided into sets representing grebes and Mirandornithes; monophyly of these sets was not enforced. Two nodes were fossil calibrated following the guidelines suggested by Parham et al. [52]. The divergence of extant grebes was calibrated at 8.7 mya based on Thiornis sociata, a grebe from the late Miocene of Spain $[53,54]$. The divergence of flamingos and grebes was calibrated at 32.6 mya based on Adelalopus hoogbutseliensis, a stem phoenicopteriform from the earliest Oligocene of Belgium [2]. Calibrations were allowed lognormal distributions with offset=calibration age and standard deviation $=1.0$. See Table 1 for the data included in each divergence analysis. All analyses were run twice for 100 million generations sampled every 1000 with burn-in of 1 million. Convergence of phylogenetic signal was tested for in Tracer 1.5.

\section{Availability of supporting data}

All supporting data are included as additional files. Newly obtained DNA sequence reads have been uploaded to Genbank (http://www.ncbi.nlm.nih.gov/). Genbank accession numbers are provided in Additional files 7 and 8.

\section{Additional files}

Additional file 1: Specimen and locality information for the Chilean Flamingo individuals included in the population genetics analysis. Additional file 2: Pairwise genetic distances between multiple individuals of each flamingo species for five nDNA loci.

Additional file 3: Pairwise genetic distances between Phoenicopterus ruber and $P$. roseus for 10 nDNA and two mtDNA loci.

Additional file 4: Primer sequences for each locus used in this study.

Additional file 5: Ancient DNA extraction and amplification methods.

Additional file 6: Sample information for individuals used in the primary phylogenetic analyses.

Additional file 7: GenBank accession numbers for sequence data used in the primary phylogenetic analyses.

Additional file 8: Sample information for the additional flamingo individuals used in the pairwise genetic distance analyses and GenBank accession numbers for associated sequence data.

\section{Competing interests}

The authors declare that they have no competing interests.

\section{Authors' contributions}

CRT carried out DNA extraction, amplification, alignment, performed all phylogenetic and divergence time analysis, and drafted the manuscript. LMO 
and MAFG carried out DNA extraction, amplification, and alignment, and helped draft the manuscript. BF carried out ancient DNA extraction, amplification and alignment. MVT conceived of the study, participated in its design and coordination, assisted with alignment and analysis, and helped to draft the manuscript. All authors read and approved the final manuscript.

\section{Acknowledgements}

We would like to thank the many people and institutes for sample collection and/or approving sample loans: Sharon Birks (Burke Museum, Seattle WA), Brooks Childress and Rebecca Lee (Wildfowl \& Wetlands Trust, Slimbridge, UK), James Dean (National Museum of Natural History, Washington DC), Jack Demboski (Denver Museum of Nature and Science, Denver CO), Becky Desjardins and John Gerwin (NC Science Museum, Raleigh NC), Steve Emslie (UNCW bird collection, Wilmington NC), Maureen Flannery and Jack Dumbacher (California Academy of Sciences, San Francisco CA), Blair Hedges (Penn State University, University Park PA), Janet Hinshaw (University of Michigan Museum of Zoology, Ann Arbor MI), Peter Houde (New Mexico State University, Las Cruces NM), Diana Humple (Point Reyes Bird Observatory, Petaluma CA), Irby Lovette (Cornell University Museum of Vertebrates, Ithaca NY), Steve Cardiff, Donna Dittman and Van Remsen (Louisiana State University Museum of Natural Science, Baton Rouge LA), Mark Robbins (Kansas University Biodiversity Institute, Lawrence KS), Paul Sweet and Joel Cracraft (American Museum of Natural History, New York NY), Krystof Ziskowski (Yale Peabody Museum of Natural History, New Haven CT), Sylvan Heights Waterfowl Centre (Scotland Neck NC), Parc des Oiseaux (Villars-les-Dombes, France), Parc Zoologique d'Amnéville (Amnéville-les-Therme, France), Salins Group and Tour du Valat (Camargue, France). We further like to thank Frank Cézilly, Arnaud Béchet and Rémi Wattier for access to samples and facilities at the Université de Bourgogne, Dijon, France, and Dan Ksepka for discussion of the flamingo and grebe fossil record. For financial support, we thank the College of Arts and Sciences and Department of Biology and Marine Biology at UNCW (to MVT), the Conseil Régional de Bourgogne (to MAFG) and the Total Foundation (to MAFG). We thank M. McCracken for providing flamingo drawings.

\section{Author details}

'Department of Biology and Marine Biology, University of North Carolina Wilmington, Wilmington, North Carolina, USA. ${ }^{2}$ Université de Bourgogne, Equipe Ecologie Evolutive, UMR CNRS 6282 Biogéosciences, 6 bd. Gabriel, Dijon 21000, France. ${ }^{3}$ Centre de Recherche de la Tour du Valat, Le Sambuc, Arles 13200, France. ${ }^{4}$ Leibniz Institute for Zoo and Wildlife Research, Department of Evolutionary Genetics, Alfred-Kowalke-Str. 17, Berlin D-10315, Germany.

Received: 20 December 2013 Accepted: 7 February 2014

Published: 1 March 2014

\section{References}

1. del Hoyo J, Elliott A, Sargatal J (Eds): Handbook of the Birds of the World. 1st edition. Barcelona, Spain: Lynx Edicions; 1992.

2. Mayr G, Smith R: Avian remains from the lowermost Oligocene of Hoogbutsel (Belgium). Bulletin de l'Institut Royal des Sciences Naturelles de Belgique Sciences de la Terre 2002, 72:139-150.

3. Gervais P: Zoologie et Paleontologie Francaise, Volume 3. Paris, France: Arthus Bertrand:1852.

4. Miller AH: The fossil flamingos of Australia. The Condor 1963, 65:289-299.

5. Harrison CJO, Walker CA: Cranial material of Oligocene and Miocene flamingos: with a description of new species from Africa. Bulletin of the British Museum (Natural History), Geology 1976, 27:305-314.

6. Van Tuinen M, Stidham TA, Hadly EA: Tempo and mode of modern bird evolution observed with large-scale taxonomic sampling. Historical Biology 2006, 18:205-221.

7. Van Tuinen M, Butvill DB, Kirsch JAW, Hedges SB: Convergence and divergence in the evolution of aquatic birds. Proceedings of the Royal Society of London B 2001, 268:1345-1350.

8. Chubb AL: New nuclear evidence for the oldest divergence among neognath birds: the phylogenetic utility of ZENK (i). Mol Phylogenet Evol 2004, 30:140-151.

9. Ericson PGP, Anderson CL, Britton T, Elzanowski A, Johansson US, Källersjö M, Ohlson JI, Parsons TJ, Zuccon D, Mayr G: Diversification of Neoaves: integration of molecular sequence data and fossils. Biology Letters 2006, 2:543-547.

10. Hackett SJ, Kimball RT, Reddy S, Bowie RCK, Braun EL, Braun MJ, Chojnowski JL, Cox WA, Han K-L, Harshman J, Huddleston CJ, Marks BD, Miglia K, Moore WS, Sheldon FH, Steadman DW, Witt CC, Yuri T: A phylogenomic study of birds reveals their evolutionary history. Science 2008, 320:1763-1768.

11. McCormack JE, Harvey MG, Faircloth BC, Crawford NG, Glenn TC, Brumfield RT: A phylogeny of birds based on over 1,500 loci collected by target enrichment and high-throughput sequencing. PLOS ONE 2013, 8:e54848.

12. Mayr G: Morphological evidence for sister group relationships between flamingos (Aves: Phoenicopteridae) and grebes (Podicipedidae). Zool J Linn Soc 2004, 140:157-169.

13. Manegold A: Two additional synapomorphies of grebes Podicipedidae and flamingo Phoenicopteridae. Acta Ornithologica 2006, 41:79-82.

14. Sangster G: A name for the flamingo-grebe clade. Ibis 2005, 147:612-615

15. Sibley CG, Ahlquist JE: Phylogeny and Classification of Birds: A Study in Molecular Evolution. New Haven, Connecticut: Yale University Press; 1990.

16. Jenkin PM: The filter-feeding and food of flamingos (Phoenicopteri). Philos Trans R Soc Lond B Biol Sci 1957, 240:401-493.

17. Mascitti V, Kravetz FO: Bill morphology of South American flamingos. The Condor 2002, 104:73-83.

18. Geraci J, Béchet A, Cézilly F, Ficheux S, Baccetti N, Samraoui B, Wattier R: Greater Flamingo colonies around the Mediterranean form a single interbreeding population and share a common history. J Avian Biol 2012, 43:341-354.

19. Zaccara S, Crosa G, Childress B, McCulloch G, Harper DM: Lesser Flamingo Phoenicopterus minor populations in eastern and southern Africa are not genetically isolated. Ostrich 2008, 79:165-170.

20. Caziani SM, Olivio OR, Ramiirez ER, Romano M, Derlindati EJ, Talamo A, Ricalde D, Quirogo C, Contreras JP, Valqui M, Sosa H: Seasonal distribution, abundance, and nesting of Puna, Andean, and Chilean Flamingos. The Condor 2007, 109:276-287.

21. Marconi P, Sureda AL, Arengo F, Aguilar MS, Amado N, Alza L, Rocha O, Torres R, Moschione F, Romano M, Sosa H, Derlindati EJ: Fourth simultaneous flamingo census in South America: preliminary results. Flamingo 2011, 18:48-53

22. Kapil R: Microsatellite-Based Genetic Profiling for the Management of Wild and Captive Flamingo Populations. PhD dissertation. Denton, Texas: University of North Texas; 2005.

23. Nadvornik P, Drobek A, Cihak K: Microsatellite markers for the study of paternity in Greater Flamingo (Phoenicopterus roseus) and Caribbean Flamingo (P. ruber). Journal of Agrobiology 2008, 25:93-96.

24. Kerr KCR, Lijtmaer DA, Barreira AS, Hebert PDN, Tubaro PL: Probing evolutionary patterns in neotropical birds through DNA barcodes. PLOS ONE 2009, 4:e4379.

25. Bucher $E H$, Curto E: Influence of long-term climatic changes on breeding of the Chilean flamingo in Mar Chiquita, Cordoba, Argentina. Hydrobiologia 2012, 697:127-137.

26. Studer-Thiersch A: What 19 years of observation on captive Greater Flamingos suggests about adaptations to breeding under irregular conditions. Waterbirds: the International Journal of Waterbird Biology 2000, 23:150-159. Special Publication 1: Conservation Biology of Flamingos.

27. Kerr KCR, Stoeckle MY, Dove CJ, Weigt LA, Francis CM, Hebert PDN: Comprehensive DNA barcode coverage of North American birds. Molecular Ecology Notes 2007, 7:535-543.

28. Gray GR: Notes on the bills of the species of flamingo (Phoenicopterus). Ibis 1869, 11:438-443.

29. Bonaparte $\mathrm{CL}$ : Excursions dans les divers musee d'Allemagne, de Hollande et de Belgique, et tableaux paralleliques de l'ordre des Echassiers. Comptes Rendus Hebdomadaires des Seances de l'Academie des Sciences 1856, 43:410-421.

30. Moore WS, Defilippis VR: The window of taxonomic resolution for phylogenies based on mitochondrial Cytochrome B. In Avian Molecular Evolution and Systematics. Edited by Mindell DP. San Diego, California: Academic Press; 1997:84-119.

31. Shufeldt RW: A study of the fossil avifauna of the Equus beds of the Oregon desert. Journal of the Academy of Natural Sciences of Philadelphia 1892, 9:389-425.

32. Miller L: A Pliocene flamingo from Mexico. The Wilson Bulletin 1944, 56:77-82.

33. Brodkorb P: A Pliocene flamingo from Florida. Natural History Miscellanea 1953, 124:1-4. 
34. Howard H: Fossil birds from Manix Lake California. Geological Survey Professional Paper 1955, 264-J:199-206.

35. Alonso RN: Valoración icnoavifaunística de ambientes boratíferos. 4th Congreso Latinoamericano de Paleontología, Santa Cruz de la Sierra, Actas 1987, 1:586-597.

36. Nasif N: Primer registro de flamencos (Phoenicopteridae) del Terciario superior, Valle del Cajón (Provincia de Catamarca, Argentina). Ameghiniana 1989, 25:169-173.

37. Ubilla M, Perea D, Tambussi C, Tonni EP: Primer registro fosil de Phoenicopteridae (Aves: Charadrifformes) para el Uruguay (Mio-Plioceno). An Acad Bras Cienc 1990, 62:61-68.

38. Rich PV, van Tets GF, Rich THV, McEvey AR: The Pliocene and Quaternary flamingoes of Australia. Memoirs of the Queensland Museum 1987, 25:207-225.

39. Olson SL, Feduccia A: Relationships and evolution of flamingos (Aves: Phoenicopteridae). Smithsonian Contributions to Zoology 1980, 316:1-84 Publications of the Smithsonian Institution.

40. Peters DS: Juncitarsus merkeli n. sp. stutzt die ableitung der flamingos von regenpfeifervogeln (Aves: Charadriiformes: Phoenicopteridae). Courier Forschungsinstitut Senckenberg 1987, 97:141-155.

41. Mayr G: The Eocene Juncitarsus - its phylogenetic position and significance for the evolution and higher-level affinities of flamingos and grebes. Comptes Rendus Palevol 2013, 13:9-18.

42. Milne-Edwards A: Recherches Anatomiques et Paleontologiques pour Servir a I'Histoire des Oiseaux Fossiles de la France, Volume 4. Paris, France: Victor Masson et Fils:1867-1871.

43. Cheneval J: Les oiseaux aquatiques (Gaviiformes a Anseriformes) du gisement aquitanien de Saint-Gerand-le-Puy (Allier, France): revision systematique. Palaeovertebrata 1984, 14:33-115.

44. Hadly EA, Ramakrishnan U, Chan YL, van Tuinen M, O'Keefe K, Spaeth PA, Conroy CJ: Genetic response to climatic change: insights from ancient DNA and phylochronology. PLoS Biology 2004, 2:e290.

45. Ogawa LM, Blanc-Goldhammer DR, Adams EL, van Tuinen M: A first molecular phylogenetic study of grebes (Aves: Podicipedidae). 126th Meeting of the American Ornithological Union, Portland, Oregon, Abstract Volume 2008:142 [http://www.pdxbirds08.org/files/pdx2008-abstracts.pdf]

46. Backström N, Fagerberg S, Ellegren H: Genomics of natural bird populations: a gene-based set of reference markers evenly spread across the avian genome. Molecular Ecology 2008, 17:964-980.

47. Tamura K, Peterson D, Peterson N, Stecher G, Nei M, Kumar S: MEGA5: Molecular evolutionary genetics analysis using maximum likelihood, evolutionary distance, and maximum parsimony methods. Mol Biol Evol 2011, 28:2731-2739.

48. Ronquist F, Teslenko M, van der Mark P, Ayres DL, Darling A, Höhna S, Larget B, Liu L, Suchard MA, Huelsenbeck JP: MrBayes 3.2: efficient Bayesian phylogenetic inference and model choice across a large model space. Systematic Biology 2012, 61:539-542.

49. Rambaut A, Drummond AJ: Tracer V1.4. 2007. http://beast.bio.ed.ac.uk/Tracer.

50. Heled J, Drummond AJ: Bayesian inference of species trees from multilocus data. Mol Biol Evol 2010, 27:570-580.

51. Drummond AJ, Suchard MA, Xie D, Rambaut A: Bayesian phylogenetics with BEAUti and the BEAST 1.7. Mol Biol Evol 2012, 29:1969-1973.

52. Parham JF, Donoghue PCJ, Bell CJ, Calway TD, Head JJ, Holroyd PA, Inoue JG, Irmis RB, Joyce WG, Ksepka DT, Patane JSL, Smith ND, Tarver JE, van Tuinen M, Yang Z, Angielczyk KD, Greenwood JM, Hipsley CA, Jacobs L, Makovicky PJ, Muller J, Smith KT, Theodor JM, Warnock RCM, Benton MJ: Best practices for justifying fossil calibrations. Systematic Biology 2012, 61:346-359.

53. Navas L: Algunos fosiles de Libros (Teruel). Boletin de la Sociedad Iberica de Ciencias Naturales 1922, 21:52-61.

54. Ksepka DT, Balanoff AM, Bell MA, Houseman MD: Fossil grebes from the Truckee formation (Miocene) of Nevada and a new phylogenetic analysis of Podicipediformes (Aves). Palaeontology 2013, 56:1-21.

doi:10.1186/1471-2148-14-36

Cite this article as: Torres et al:: A multi-locus inference of the evolutionary diversification of extant flamingos (Phoenicopteridae). BMC Evolutionary Biology 2014 14:36

\section{Submit your next manuscript to BioMed Central and take full advantage of:}

- Convenient online submission

- Thorough peer review

- No space constraints or color figure charges

- Immediate publication on acceptance

- Inclusion in PubMed, CAS, Scopus and Google Scholar

- Research which is freely available for redistribution

Submit your manuscript at www.biomedcentral.com/submit
C BioMed Central 